\title{
Prevalence, circumstances and consequences of falls among community-dwelling older people: results of the 2009 NSW Falls Prevention Baseline Survey
}

\author{
Andrew J. Milat ${ }^{\mathrm{A}, \mathrm{E}}$, Wendy L. Watson ${ }^{\mathrm{B}}$, \\ Claire Monger $^{\mathrm{C}}$, Margo Barr ${ }^{\mathrm{D}}$, Michael Giffin ${ }^{\mathrm{D}}$ \\ and Michael Reid ${ }^{\mathrm{C}}$ \\ ${ }^{\mathrm{A}}$ The Sax Institute (formerly ${ }^{\mathrm{C}}$ ) \\ ${ }^{\mathrm{B}}$ NSW Injury Risk Management Centre, The University \\ of New South Wales \\ ${ }^{\mathrm{C}}$ Centre for Health Advancement, NSW Department of Health \\ ${ }^{\mathrm{D}}$ Centre for Epidemiology and Research, NSW Department \\ of Health \\ ${ }^{\mathrm{E} C o r r e s p o n d i n g ~ a u t h o r . E m a i l: ~ a n d r e w . m i l a t @ s a x i n s t i t u t e . o r g . a u ~}$
}

\begin{abstract}
Aim: To describe the prevalence, circumstances and consequences of falls among community-dwelling older people in NSW using data from the 2009 NSW Falls Prevention Baseline Survey. Methods: Telephone interviews with a random sample of $5681 \mathrm{NSW}$ residents aged 65 years and over were conducted in 2009. Results: Of those surveyed, $25.6 \%$ reported falling in the last year. Of those who fell, $61.2 \%$ fell once, $21.4 \%$ fell twice, $7.8 \%$ fell three times, and $9.5 \%$ fell four or more times in the last year. Sixty-six percent of those who fell in the last year were injured and $20.0 \%$ visited a hospital as a result of a fall. The most common injuries were cuts, grazes or bruises $(71.0 \%)$ and sprains or strains $(9.9 \%)$. Conclusion: The findings of this survey are consistent with previous findings in the published fall injury prevention literature. The results from the survey will assist in the design of community oriented fall injury prevention strategies and will form the baseline measure for the evaluation of the impact of these strategies in NSW.
\end{abstract}

With an ageing population, falls among older people are a significant public health issue. ${ }^{1-5}$ No other single injury cause, including road trauma, costs the New South Wales (NSW) health system more. ${ }^{2}$ Even non-injurious falls can have negative impacts such as loss of confidence and activity restriction. ${ }^{3}$ Retrospective community-based studies and surveys consistently report that approximately $30 \%$ of older people experience one or more falls each year. ${ }^{6-11}$ In addition, the prevalence of falls increases with age and older people who have suffered a fall are at increased risk of falling again. ${ }^{12}$

Previous studies in NSW and elsewhere have shown that about $50-60 \%$ of falls among community-dwelling older people occur within their own home and yard, with most falls occurring on level surfaces in commonly used rooms such as the bedroom, lounge and kitchen. ${ }^{13-15}$ Depending on the population studied and the definition of injury used, $22-60 \%$ of older people suffer injuries from falls, $10-15 \%$ suffer serious injuries, 2-6\% suffer fractures, and $0.2-1.5 \%$ suffer hip fractures. ${ }^{12}$ The most commonly reported injuries are superficial cuts and abrasions, bruises and sprains. ${ }^{12,14-18}$

Although previous population health surveys have described the epidemiology of falls, ${ }^{9-11}$ they have not been conducted with as large a sample and have not provided the breadth of data on falls history, circumstances surrounding falls, consequences, health status, falls risk and protective factors, contact with health professionals, falls prevention knowledge and exposure to preventative measures. Consequently the 2009 NSW Falls Prevention Baseline Survey (the Survey) was conducted to provide current and comprehensive data to assist in the evaluation of the impact of the NSW Health Plan for Prevention of Falls and Harm from Falls Among Older People: 2011-2015. ${ }^{19}$

The full results of the Survey are reported elsewhere. ${ }^{20}$ This paper focuses specifically on falls prevalence and the circumstances and consequences of falls.

\section{Methods}

Survey instrument

The Survey instrument was developed by the Centre for Health Advancement (NSW Department of Health) and 
the NSW Injury Risk Management Research Centre (University of NSW). Questions were field-tested prior to inclusion in the Survey. The Survey defined a fall as: 'an unexpected event in which the participant comes to rest on the ground or floor or a lower level'. ${ }^{12}$ Multiple responses were allowed for questions pertaining to injuries suffered from the most recent fall and perceived causes of the most recent fall.

The instrument was translated into five languages: Arabic, Chinese, Greek, Italian and Vietnamese. A shorter version of the instrument was administered to the main carers of 361 participants unable to answer on their own behalf.

The target population for the Survey was all NSW residents aged 65 years and over living in households with private telephones. The target sample comprised a random sample of approximately 625 people in each of the eight former NSW area health services for a total sample of 5681 .

The sampling frame was developed using records from the Australia on Disk ${ }^{21}$ electronic white pages (phone book) which were geocoded using MapInfo ${ }^{22}$ mapping software. The geocoded telephone numbers were assigned to statistical local areas and former area health services. The proportion of numbers for each telephone prefix by former area health service was calculated. All prefixes were expanded with suffixes ranging from 0000 to 9999 . The resulting list was then matched back to the electronic phone book. All numbers that matched numbers in the electronic phone book were flagged and the number was assigned to the relevant geocoded former area health service. Unlisted numbers were assigned to the former area health service containing the greatest proportion of numbers with that prefix. Numbers were then filtered to eliminate contiguous unused blocks of greater than 10 numbers. The remaining numbers were checked against the business numbers in the electronic phone book to eliminate business numbers. Finally, numbers were randomly sorted.

Households were contacted using random digit dialling and one eligible person from the household was selected for inclusion in the Survey. Interviews were carried out continuously between March and July 2009 by trained interviewers at the NSW Health Survey Program computer-assisted telephone interviewing (CATI) facility and the McNair Ingenuity Research Ltd CATI facility.

Up to seven calls were made to establish initial contact with a household, and five calls were made in order to contact a selected respondent. A more detailed description of the Survey methods is available in the full report. ${ }^{20}$

The conduct of the Survey was approved by NSW Health's Population and Health Services Research Ethics Committee.

\section{Data analysis}

Call and interview data were analysed using SAS software (version 9.1.3, SAS Institute, Cary, NC, USA). The SURVEYFREQ procedure in SAS was used to analyse the data and calculate point estimates and $95 \%$ confidence intervals for the estimates. The SURVEYFREQ procedure calculates standard errors adjusted for the design effect factor (the variance for a non-random sample divided by the variance for a simple random sample). Comparisons against the overall statewide prevalence were made for each factor under investigation by gender, age group and urban versus rural health areas. For the purposes of the Survey, 'urban' meant that the respondent lived in one of the four former area health services designated as metropolitan: Northern Sydney Central Coast, South Eastern Sydney Illawarra, Sydney South West or Sydney West. 'Rural' meant that the respondent lived in one of the four former area health services designated as rural: Greater Southern, Greater Western, Hunter New England or North Coast.

Prevalence measures were calculated using weighted data. Further information on the weighting and data analysis process is provided elsewhere. ${ }^{20,23}$

\section{Response rate}

In total, 5681 interviews were conducted with NSW residents aged 65 years and over, with at least 675 interviews in each former area health service. The overall response rate was $60.8 \%$, with $4.9 \%$ of interviews conducted in a language other than English. The majority of participants answered questions on their own behalf. However, proxy respondents were required for 361 participants $(6.4 \%)$ unable to answer on their own behalf due to communication difficulties or cognitive impairment.

\section{Results}

\section{Falls in the last 12 months}

In $2009,25.6 \%$ of older people in NSW reported falling at least once in the last 12 months (Table 1). There was no significant difference in falls prevalence in the last 12 months between males and females. A significantly lower proportion of older adults aged 65-69 years $(21.5 \%$, $p=0.000004)$, and a significantly higher proportion of older adults aged $85-89$ years $(34.0 \%, p=0.000743)$ and 90 years and over $(35.9 \%, p=0.024429)$ had fallen in the last 12 months, compared with the overall older adult population.

\section{Number of falls in the last 12 months}

Among those older adults who had fallen in the last 12 months, the majority (61.2\%) fell only once, $21.4 \%$ fell twice, $7.8 \%$ fell three times, and $9.5 \%$ fell four or more times. Overall, the average number of falls increased with 
Table 1. Prevalence of falls, fall-related injury and level of treatment in the last 12 months, adults aged 65 years and over, NSW, 2009

\begin{tabular}{|c|c|c|c|c|c|}
\hline \multirow{2}{*}{$\begin{array}{l}\text { Age } \\
\text { (years) }\end{array}$} & \multirow{2}{*}{$\begin{array}{l}\text { Fell in last } \\
12 \text { months } \\
\%(95 \% \mathrm{Cl})\end{array}$} & \multicolumn{4}{|c|}{ Persons injured and level of treatment } \\
\hline & & $\begin{array}{c}\text { Injured } \\
\%(95 \% \mathrm{Cl})\end{array}$ & $\begin{array}{l}\text { Required a visit } \\
\text { to hospital } \\
\%(95 \% \mathrm{Cl})\end{array}$ & $\begin{array}{l}\text { Required admission } \\
\text { to hospital } \\
\%(95 \% \mathrm{Cl})\end{array}$ & $\begin{array}{c}\text { Required non- } \\
\text { hospital treatment } \\
\%(95 \% \mathrm{Cl})\end{array}$ \\
\hline $65-69$ & $21.5(19.3-23.6)$ & $65.0(59.7-70.4)$ & $17.4(12.9-21.9)$ & $7.3(4.4-10.2)$ & $19.2(14.7-23.7)$ \\
\hline $70-74$ & $24.5(21.9-27.1)$ & $66.5(60.8-72.2)$ & $18.1(13.5-22.6)$ & $8.2(4.9-11.5)$ & $23.2(18.1-28.3)$ \\
\hline $75-79$ & $26.9(23.9-29.9)$ & $65.3(59.1-71.5)$ & $18.1(13.1-23.1)$ & $11.6(7.5-15.6)$ & $22.5(17.2-27.9)$ \\
\hline $80-84$ & $27.8(24.4-31.2)$ & $63.8(57.0-70.6)$ & $20.2(14.6-25.8)$ & $11.6(7.1-16.1)$ & $21.7(16.0-27.5)$ \\
\hline $85-89$ & $34.0(28.9-39.2)$ & $72.1(63.9-80.4)$ & $31.5(22.6-40.4)$ & $19.4(11.7-27.1)$ & $27.3(18.6-36.0)$ \\
\hline $90+$ & $35.9(26.8-44.9)$ & $70.1(55.5-84.7)$ & $26.3(11.0-41.6)$ & $14.8(0.2-29.3)$ & $34.9(18.9-51.0)$ \\
\hline All & $25.6(24.3-26.9)$ & $66.1(63.4-68.9)$ & $20.0(17.6-22.3)$ & $10.7(8.8-12.5)$ & $22.7(20.2-25.2)$ \\
\hline $\begin{array}{l}\text { No. of respondents } \\
\text { on which estimates } \\
\text { are based }\end{array}$ & $n=5662$ & $n=1473$ & $n=1476$ & $n=1476$ & $n=1469$ \\
\hline
\end{tabular}

Denominator is persons who fell at least once.

Source: NSW Falls Prevention Baseline Survey (HOIST). Centre for Epidemiology and Research and Centre for Health Advancement, NSW Department of Health.

Table 2. Injuries reported from most recent fall, adults aged 65 years and over who were injured in a fall in the last 12 months, NSW, 2009

\begin{tabular}{lccc}
\hline Response & $\begin{array}{c}\text { Males } \\
\%(95 \% \mathrm{Cl})\end{array}$ & $\begin{array}{c}\text { Females } \\
\%(95 \% \mathrm{Cl})\end{array}$ & $\begin{array}{c}\text { Persons } \\
\%(95 \% \mathrm{Cl})\end{array}$ \\
Head injury (including eyes and teeth) & $3.5(1.2-5.9)$ & $3.2(1.6-4.8)$ & $3.3(2.0-4.7)$ \\
Spinal injury & $1.6(0.0-3.2)$ & $0.6(0.0-1.1)$ & $1.0(0.2-1.7)$ \\
Fractured arms or hands & $1.6(0.0-3.2)$ & $0.6(0.0-1.1)$ & $1.0(0.2-1.7)$ \\
Fractured ribs or sternum & $2.2(0.6-3.7)$ & $3.1(1.5-4.7)$ & $2.7(1.6-3.9)$ \\
Fractured hip, femur or pelvis & $1.8(0.1-3.5)$ & $2.0(0.8-3.3)$ & $1.9(0.9-2.9)$ \\
Fractured lower leg, knees or feet & $2.9(0.9-4.9)$ & $3.7(2.0-5.4)$ & $3.4(2.1-4.7)$ \\
Sprain or strain & $12.1(8.2-16.1)$ & $8.4(5.8-11.0)$ & $9.9(7.7-12.1)$ \\
Dislocation & $1.2(0.0-2.6)$ & $1.1(0.2-2.0)$ & $1.2(0.4-1.9)$ \\
Cuts, grazes or bruises & $69.8(64.2-75.5)$ & $71.8(67.5-76.1)$ & $71.0(67.6-74.5)$ \\
Other & $13.2(9.1-17.3)$ & $14.9(11.7-18.2)$ & $14.2(11.7-16.8)$ \\
\hline Respondents could provide more than one response. Estimates are based on 915 respondents. & \\
Source: NSW Falls Prevention Baseline Survey (HOIST). Centre for Epidemiology and Research and Centre for Health Advancement, \\
NSW Department of Health.
\end{tabular}

age from 1.78 among those aged 65-69 years to 2.67 among those aged 90 years and over.

\section{Persons injured as a result of falls}

Of those persons who fell in the last 12 months, 66.1\% sustained an injury as a result of a fall (Table 1). There was no significant difference between age groups; however, a significantly lower proportion $(p=0.000111)$ of males $(60.0 \%)$ than females $(71 \%)$, and a significantly higher proportion of adults $(p=0.020515)$ in metropolitan health areas $(68.5 \%)$ than rural health areas $(62.1 \%)$ experienced an injury as a result.

When asked about their most recent fall, the most common injuries reported were cuts, grazes or bruises (71\%) and sprains or strains $(9.9 \%)$ (Table 2$)$. Respondents could report more than one type of injury.

\section{Persons requiring a visit to hospital as a result of falls}

Among older adults who had fallen in the last 12 months, $20 \%$ required a visit to hospital as a result of a fall (Table 1 ). There was no significant difference between males and females. Among those who fell, a significantly higher proportion of older adults aged 85-89 years (31.5\%, $p=0.006096$ ) required a visit to hospital, compared with the overall older adult population.

\section{Persons admitted to hospital as a result of falls}

Among older adults who had fallen in the last 12 months, $10.7 \%$ required admission to hospital as a result of a fall 
Table 3. Activities reported being undertaken when most recent fall occurred, adults aged 65 years and over who had a fall in the last 12 months, NSW, 2009

\begin{tabular}{lccc}
\hline Response & $\begin{array}{c}\text { Males } \\
\%(95 \% \mathrm{Cl})\end{array}$ & $\begin{array}{c}\text { Females } \\
\%(95 \% \mathrm{Cl})\end{array}$ & $\begin{array}{c}\text { Persons } \\
\%(95 \% \mathrm{Cl})\end{array}$ \\
\hline Hurrying & $4.7(2.8-6.6)$ & $7.8(5.7-10.0)$ & $6.4(5.0-7.9)$ \\
Steps, stairs, kerb or gutter & $9.8(7.3-12.3)$ & $11.6(9.2-14.0)$ & $10.8(9.1-12.5)$ \\
Carrying or bending activities & $14.4(11.2-17.6)$ & $17.0(14.1-19.9)$ & $15.8(13.7-18.0)$ \\
Walking & $38.9(34.4-43.5)$ & $47.6(43.9-51.4)$ & $43.8(40.9-46.7)$ \\
Physical work or chores & $17.5(14.0-20.9)$ & $16.2(13.4-18.9)$ & $16.7(14.6-18.9)$ \\
Bathing, dressing or on toilet & $5.2(3.0-7.4)$ & $4.1(2.7-5.6)$ & $4.6(3.3-5.8)$ \\
Activity off the ground & $5.7(3.6-7.7)$ & $2.6(1.1-4.0)$ & $3.9(2.7-5.2)$ \\
Sports, exercise or physical activity & $7.8(5.4-10.2)$ & $2.3(1.1-3.5)$ & $4.7(3.5-6.0)$ \\
Effects of medication, dizziness, sleeping or fainting & $3.2(1.6-4.8)$ & $5.5(3.8-7.3)$ & $4.5(3.3-5.7)$ \\
Other & $4.2(2.4-6.0)$ & $2.3(1.2-3.5)$ & $3.2(2.2-4.2)$ \\
\hline Respondents could provide more than one response. Estimates are based on 1465 respondents. & & \\
Source: NSW Falls Prevention Baseline Survey (HOIST). Centre for Epidemiology and Research and Centre for Health Advancement, \\
NSW Department of Health.
\end{tabular}

(Table 1). There was no significant difference between males and females. Among those who fell, a significantly lower proportion of older adults aged $65-69$ years $(7.3 \%$, $p=0.011001)$, and a significantly higher proportion of older adults aged $85-89$ years $(19.4 \%, p=0.016115)$, required admission to hospital, compared with the overall older adult population. Among those who fell, a significantly higher proportion $(p=0.011548)$ of older adults in metropolitan health areas $(12.2 \%)$ than rural health areas $(7.9 \%)$ required admission to hospital as a result of a fall.

\section{Persons requiring other non-hospital medical treatment as a result of falls}

Among older adults who had fallen in the last 12 months, $22.7 \%$ required medical treatment without hospitalisation as a result of a fall. A significantly lower proportion $(p=0.033542)$ of males $(19.7 \%)$ than females $(25.1 \%)$ required medical treatment without hospitalisation as a result of a fall. There was no significant difference among age groups or between metropolitan and rural health areas.

\section{Activities undertaken when most recent fall occurred}

The most common activities undertaken when the most recent fall occurred were: walking (43.8\%); physical work or chores (16.7\%); carrying or bending activities (15.8\%); and negotiating steps, stairs, kerbs or gutters $(10.8 \%)$ (Table 3).

\section{Perceived causes of most recent fall}

The most common perceived causes of the most recent fall were: tripped or slipped (27.4\%); surrounding hazards, for example wet or uneven floor (21.8\%); misjudged, overbalanced, or over-reached (17.8\%); and fainting, dizziness, illness, or legs gave way (17.7\%). Respondents could report more than one cause.

\section{Discussion}

The results of the 2009 NSW Falls Prevention Baseline Survey ${ }^{20}$ are consistent with findings reported in the Australian and international literature. For example, in NSW in 2009, 25.6\% of older adults reported falling in the last 12 months compared with approximately $30 \%$ in the published literature. ${ }^{6-11}$ The Survey also confirmed that many older people living in the community fall more than once and that the frequency of falls experienced by older people increases with age. ${ }^{10,11}$ The most common injuries reported in the Survey by older people who had fallen were similar to those reported in the literature (relatively minor cuts, grazes or bruises). Fractured hips were a relatively uncommon outcome with only $1.9 \%$ of persons in the Survey injured as the result of a fall reporting a fractured hip, femur or pelvis compared to a range of $0.2-1.5 \%$ for hip fractures in the literature. ${ }^{12}$ However, it is possible that the Survey underestimated the frequency of these serious injuries as older people who had moved to residential care or died as a result of such injuries would not be included in the data. Consistent with the literature, most falls occurred in the home environment. ${ }^{13-15}$

There were, however, some exceptions to the homogeneity of these results. Of those who fell, $66.1 \%$ reported experiencing an injury compared to estimates in the literature ranging between $22 \%$ and $60 \% .{ }^{12}$ While the prevalence of injury may vary depending on the population under study, the definition of an injury also varies considerably between studies. In this case, minor injuries such as bruises, cuts and abrasions were included and this may account for the higher prevalence of injury reported here.

These findings on the prevalence, type and place of injury can assist in falls prevention program design and implementation. Importantly, the Survey also provides a 
baseline for the evaluation of the impact of NSW Health Plan for Prevention of Falls and Harm from Falls Among Older People: $2011-2015^{19}$ by providing not only much needed data on falls prevalence, but state and area measures of risk and protective factors, contact with health professionals, falls prevention knowledge and exposure to preventative interventions. Together these measures are a central part of the NSW Falls Plan Evaluation Framework. This framework will also include the ongoing monitoring of a subset of fall-related questions in the continuous NSW Population Health Survey and a follow-up survey in 2015.

Despite the representative nature of the Survey sample, there are a number of limitations which should be noted. The falls status data from the Survey may be subject to recall bias as respondents were asked to report on falls and treatment for fall-related injuries in the previous 12 months. However, a review of cohort studies by Ganz et $\mathrm{al}^{24}$ showed that, in three studies for which data were available, recall of any fall in the previous year is relatively specific (91-95\%), but somewhat less sensitive (80-89\%) than intensive prospective data collection involving postcards or diaries. One study conducted in Australia also showed that individuals who suffered an injurious fall were significantly more likely to recall their falls than those who were not injured. ${ }^{25}$

Despite the large sample size, caution should be used in interpreting results where wide confidence intervals are reported. As the Survey relied on self-reporting, agerelated cognitive deficits may have compromised accurate reporting in some respondents. To minimise this risk interviewers were trained in the delivery of surveys to older people and proxy respondents were allowed when eligible participants were unable to complete interviews themselves.

Despite these limitations it is encouraging that the 2009 Survey results, for the most part, are consistent with the literature. The consistency in findings may suggest that the aetiology of falls in community-dwelling older people in developed countries remain relatively stable over time, as evidenced by the fact that some of the data in the literature was generated over three decades.

\section{Conclusion}

Despite the different methodologies described in the literature to ascertain fall prevalence, circumstances and the consequences of falls, the findings from this large, representative, population level survey of community-dwelling older people are similar to the body of evidence in this area. The results of this Survey provide information relevant to the design of falls prevention programs and an important set of measures of the impact of falls prevention policy implementation in NSW.
The New South Wales Falls Prevention Baseline Survey: 2009 Report is available in both HTML and PDF versions from the NSW Department of Health website at: www.health.nsw.gov.au.

\section{Acknowledgments}

The authors would like to acknowledge the important contribution of Frances Garden, Matthew Gorringe, Lara Harvey, Naomi Jackson, Ming Lin, Don Bryson-Taylor, Ray Ferguson and Lindy Fritsche to the development, data collection and analysis of the Survey.

\section{References}

1. National Ageing Research Institute. An analysis of research on preventing falls and falls injuries in older people: Community, residential care and hospital settings. Canberra: Commonwealth of Australia; 2004.

2. NSW Department of Health. Management Policy to Reduce Fall Injury Among Older People - Detailed strategies and performance requirements 2003-2007. North Sydney: NSW Department of Health; 2003.

3. Tinetti ME, Williams CS. The effect of falls and fall injury on functioning in community-dwelling older persons. J Gerontol A Biol Sci Med Sci 1998; 53(2): M112-9.

4. American Geriatrics Society. British Geriatrics Society and American Academy of Orthopaedic Surgeons Panel on Falls Prevention Guideline for the prevention of falls in older persons. J Am Geriatr Soc 2001; 49(5): 664-72.

5. Treasury of the Commonwealth of Australia. Intergenerational Report 2010: Australia to 2050, Future Challenges. Canberra: Commonwealth of Australia; 2010. Available from: www.treasury.gov.au/igr/igr2010 (Cited 9 July 2010.)

6. Campbell AJ, Reinken J, Allan BC, Martinez GS. Falls in old age: a study of frequency and related clinical factors. Age Ageing 1981; 10(4): 264-70. doi:10.1093/ageing/10.4.264

7. Prudham D, Grimley-Evans J. Factors associated with falls in the elderly: a community study. Age Ageing 1981; 10(3): 141-6.

8. Blake A, Morgan K, Bendall MJ, Dallosso H, Ebrahim SB, Arie TH et al. Falls by elderly people at home: prevalence and associated factors. Age Ageing 1988; 17(6): 365-72. doi:10.1093/ageing/17.6.365

9. Steven JA, Ryan G, Kresnow M. Fatalities and injuries from falls among older adults - United States, 1993-2003 and 2001-2005. MMWR 2006; 55(45): 1221-4.

10. NSW Department of Health. The epidemiology of falls in older people in NSW. North Sydney: NSW Department of Health; 1994.

11. Gill T, Taylor AW, Pengelly A. A population-based survey of factors relating to the prevalence of falls in older people. Gerontology 2005; 51(5): 340-5. doi:10.1159/000086372

12. Lord S, Sherrington C, Menz H, Close J. Falls in older people: risk factors and strategies for prevention. Cambridge: Cambridge University Press; 2008.

13. Luukinen H, Koski K, Laippala P, Kivelä SL. Predictors for recurrent falls among the home-dwelling elderly. Scand J Prim Health Care 1995; 13(4): 294-9. doi:10.3109/ 02813439508996778

14. Campbell AJ, Borrie MJ, Spears GF, Jackson SL, Brown JS, Fitzgerald JL. Circumstances and consequences of falls 
experienced by a community population 70 years and over during a prospective study. Age Ageing 1990; 19(2): 136-41. doi:10.1093/ageing/19.2.136

15. Gibson MJ, Andres RO, Isaacs B, Radebaugh T, Worm-Petersen $\mathrm{J}$. The prevention of falls in later life. A report of the Kellogg International Work Group on the Prevention of Falls by the Elderly. Dan Med Bull 1987; 34(Suppl. 4): 1-24.

16. Centers for Disease Control and Prevention. Falls among older Americans: CDC prevention efforts. CDC: Atlanta; 2002.

17. Resnick B, Junlapeeya P. Falls in a community of older adults: findings and implications for practice. Appl Nurs Res 2004; 17(2): 81-91.

18. Cripps R, Carman J. Falls by the elderly in Australia: trends and data for 1998. Injury Research and Statistics Series (AIHW cat. No. INJCAT 35). Adelaide: Australian Institute of Health and Welfare; 2001.

19. NSW Department of Health. NSW Health Plan for Prevention of Falls and Harm from Falls Among Older People: 2011-2015. North Sydney: NSW Department of Health; 2011.
20. Centre for Health Advancement and Centre for Epidemiology and Research. New South Wales Falls Prevention Baseline Survey: 2009 Report. North Sydney: NSW Department of Health; 2010. Available from: www.health.nsw.gov.au (Cited 10 March 2011.)

21. Australia on Disk [software]. Sydney: Australia on Disk; 2004.

22. MapInfo [software]. Troy, NY: MapInfo Corporation; 1997.

23. Steel D. New South Wales Population Health Survey: Review of weighting procedures. North Sydney: NSW Department of Health; 2006. Available from: www.health.nsw.gov.au/pubs/ 2006/review_weighting.html (Cited 6 July 2010.)

24. Ganz D, Higashi T, Rubenstein LZ. Monitoring falls in cohort ctudies of community-dwelling older people: effect of the recall interval. J Am Geriatr Soc 2005; 53(12): 2190-4. doi:10.1111/ j.1532-5415.2005.00509.x

25. Peel N. Validating recall of falls by older people. Accid Anal Prev 2000; 32(3): 371-2. doi:10.1016/S0001-4575(99) 00066-4 